\title{
The Transport of Exogenous Cholesterol in the Rabbit
}

\author{
I. ROLE OF CHOLESTEROL ESTER OF LYMPH CHYLOMICRA AND \\ LYMPH VERY LOW DENSITY LIPOPROTEINS IN \\ ABSORPTION
}

\author{
L. L. Rudel, M. D. Monris, and J. M. Felts \\ From the Banting and Best Department of Medical Research, University of \\ Toronto, Toronto, Ontario, Canada and Departments of Biochemistry and \\ Pediatrics, University of Arkansas Medical Center, Little Rock, Arkansas 72201
}

\begin{abstract}
A в S TRACT Thoracic lymph duct cannulations were performed shortly after a meal in rabbits trained to ingest a moderate fat, low cholesterol diet. A tracer dose of cholesterol- ${ }^{3} \mathrm{H}$ was administered to label exogenous (dietary) cholesterol during absorption. Sequential lymph samples were collected up to $24 \mathrm{hr}$ postprandially, after which ultracentrifugal fractionation of lymph lipoproteins was carried out. The $\mathrm{d}<1.006$ lipoproteins were separated into two classes, chylomicra and very low density lipoproteins (VLDL).
\end{abstract}

A comparison was made between chylomicra and VLDL of lymph in the transport of exogenous cholesterol after ingestion of a single meal. The per cent of exogenous cholesterol present in VLDL of sequential lymph collections progressively increased with time after a meal and by $18 \mathrm{hr}$ had reached a value of $80 \%$ or greater. In chylomicra the per cent of exogenous cholesterol of sequential lymph collections progressively decreased. Therefore, exogenous cholesterol was preferentially transported in VLDL compared with chylomicra.

Cholesterol ester specific activity (CESA) of lymph chylomicra and VLDL increased at a more rapid rate than free cholesterol specific activity (FCSA). CESA of VLDL was three times higher than FCSA at the maximum. Exogenous cholesterol which appeared in both chylomicra and VLDL was consistently $80 \%$ esterified.

A preliminary report of these studies has appeared in Physiologist. 1970. 13: 298.

The present address for Doctors Rudel and Felts is the Iipid Research Laboratory, Veterans Administration Hospital, San Francisco, Calif. Dr. Rudel was a Postdoctoral Fellow of the Canadian Heart Foundation during completion of this work.

Received for publication 22 February 1972 and in revised form 27 June 1972. while the per cent of total cholesterol esterified decreased with time and was significantly lower than that for exogenous cholesterol from 6 to $24 \mathrm{hr}$ postprandially. These results demonstrate preferential esterification of exogenous cholesterol during absorption and indicate that a mechanism exists within the intestinal mucosal cell to maintain both free and esterified exogenous cholesterol in a chemically distinct pool from endogenous cholesterol during incorporation into both chylomicra and VLDL.

\section{INTRODUCTION}

In some species, most notably the rabbit (1), increased amounts of dietary cholesterol lead to dramatically elevated plasma cholesterol concentrations. In contrast, the rat and dog do not exhibit this response to dietary cholesterol alone (1). In the present work we have studied exogenous cholesterol absorption in the rabbit since this process is likely to be related to the high susceptibility of this species to experimental atherosclerosis. We have specifically examined the role of lymph chylomicra and very low density lipoproteins (VLDL) ${ }^{1}$ in exogenous cholesterol transport in light of an earlier suggestion made by Zilversmit, Courtice, and Fraser (2) that the rabbit is a species in which thoracic duct lymph contains comparatively high VLDL levels. The relative importance of chylomicra and VLDL in the transport of exogenous cholesterol has not been investigated previously, although a primary role for chylomicra has long been assumed (3). Our studies were carried out on rabbits

${ }^{1}$ Abbreciations used in this paper: CESA, cholesterol ester specific activity; FCSA, free cholesterol specific activity; p.p., postprandially; VLDL, very low density lipoproteins. 
after ingestion of a single meal. In these studies, a low cholesterol-containing diet was fed. These animals will serve as controls for subsequent studies on rabbits fed high cholesterol-containing diets.

\section{METHODS}

Animals. Male New Zealand white rabbits, weighing between 2.5 and $3.5 \mathrm{~kg}$ were used in these experiments. They were trained to eat two 45-g meals daily in 1-hr feeding periods. The diet consisted of commercial rabbit pellets (Rockland, Teklad, Inc., Monmouth, Ill.) coated with corn oil and cholesterol. By analysis, the diet contained $4.7 \%$ triglyceride and $0.08 \%$ cholesterol. Experiments were carried out after animals had ingested their normal morning meal, in which case they obtained $2.11 \mathrm{~g}$ of triglyceride and $36 \mathrm{mg}$ of cholesterol. Animals used for these studies had been on this diet for at least 1 month, and plasma cholesterol concentrations remained in the normal range as determined by assay.

Reagents. Reagent grade solvents (Fisher Scientific Co., Ltd., Montreal, Canada) were used for lipid extraction and thin-layer chromatography (TLC). The cholesterol-7 $\alpha^{-3} \mathrm{H}$ was purchased from New England Nuclear Corp., Boston, Mass., and was purified on TLC before use (4). Corn oil (Mazola, Canada Starch Company, Ltd., Montreal) and cholesterol (ICN Nutritional Biochemicals, Cleveland, Ohio) were added as dietary supplements. Sodium glycodeoxycholate was purchased from Sigma Chemical Company, St. Louis, Mo.

Cannulation and handling of lymph samples. Between 2 and $2 \frac{1}{2} \mathrm{hr}$ after feeding, animals were anesthetized with sodium pentothal (Abbott Laboratories, Ltd., Montreal) after which a laparotomy was performed. The left kidney was tied off and removed to facilitate access to the thoracic duct. This vessel lies deep to the aorta, and was exposed just anterior to the level of the adrenals. After tying off the thoracic duct anterior to the point of cannulation, it was cannulated using Silastic tubing (Dow Corning Corp., Midland, Mich.; 0.025 inches, I.D., 0.047 inches O.D.) and the cannula was fixed in place using tissue glue (Eastman 910 Adhesive, methyl 2-cyanoacrylate, Eastman Kodak Co., Rochester, N. Y.). The cannula was exteriorized through a stab wound in the left side, after which the abdominal incision was closed and the animal was placed in a prone position and restrained. Collection of lymph was begun $3 \mathrm{hr}$ postprandially (p.p.). Sequential lymph samples were collected in polycarbonate tubes at room temperature usually in 3-hr time intervals for a total time of $21 \mathrm{hr}$. Immediately after collection, $5 \%$ disodium ethylenediaminetetraacetate (EDTA), $\mathrm{pH} 7.0$, was added to a final concentration in lymph of $0.1 \%$ and samples were transferred to a $15^{\circ} \mathrm{C}$ refrigerator. Preparative ultracentrifugation was begun within $24 \mathrm{hr}$ of collection. Animals were kept hydrated throughout the collection period by continuous intravenous infusion of $0.9 \% \mathrm{NaCl}(4 \mathrm{ml} / \mathrm{hr})$ into an ear vein. Rate of lymph flow was relatively constant between 3 and $4 \mathrm{ml} / \mathrm{hr}$ in animals treated in this way.

In some experiments, a tracer dose of $30 \mu \mathrm{Ci}\left(66 \times 10^{\circ}\right.$ $\mu \mathrm{g})$ of cholesterol- $7 \alpha{ }^{3} \mathrm{H}$ was added to the regular meal. In other cases, the same dose of cholesterol- ${ }^{\mathrm{B}} \mathrm{H}$ was administered intraduodenally as an emulsion or as a micellar solution after cannulation had taken place. The emulsion was prepared by adding one drop of corn oil to the cholesterol- ${ }^{3} \mathrm{H}$ dissolved in benzene, evaporating the benzene under $\mathrm{N}_{2}$, and emulsifying by sonication in $1 \mathrm{ml}$ of $10 \%$ sodium glycodeoxycholate, $\mathrm{pH}$ 7.4. Sonication was carried out for $15 \mathrm{sec}$ at $7 \mathrm{kc} / \mathrm{sec}$, using the "Needle" probe on a Bronwill Biosonik BP-111 (model 300W, Bronwill Scientific, Inc., Rochester, N. Y.). A clear micellar suspension was prepared by adding about $10 \mathrm{mg}$ of monoolein to the benzene solution of cholesterol- ${ }^{3} \mathrm{H}$, after which the benzene was evaporated under $\mathrm{N}_{\mathbf{2}}$ and $2 \mathrm{ml}$ of $20 \mathrm{~mm}$ sodium glycodeoxycholate, $\mathrm{pH} \mathrm{7.4,} \mathrm{was} \mathrm{added.} \mathrm{To} \mathrm{assure} \mathrm{complete} \mathrm{solubilization,} \mathrm{this}$ mixture was then treated by sonication as above.

At the end of the experimental period, plasma samples were taken from those animals which had received the cholesterol- ${ }^{3} \mathrm{H}$ dose as a micellar suspension. Such samples contained negligible amounts of radioactivity, indicating that the collection of intestinal lymph produced throughout this period had been complete.

Fractionation of lymph samples. Lymph was subfractionated by ultracentrifugation in a L2-65B ultracentrifuge (Beckman Instruments, Inc., Palo Alto, Calif.) using a SW-40 swinging bucket rotor. The method, described in detail elsewhere, ${ }^{2}$ consists of sequential centrifugations at $\mathrm{d}=1.006$ to separate chylomicra (operational definition $S_{f}>400$ ) and VLDL (operational definition $S_{f}$ 20-400). Differences in mobility as seen on agarose electrophoresis ${ }^{2}$ performed according to Noble (5), indicated only very small amounts of cross contamination occurred in the separation of chylomicra and VLDL by this method. Greater than $95 \%$ of exogenous cholesterol $-{ }^{3} \mathrm{H}$ recovered in lymph was found in lymph $d<1.006$ lipoproteins, and greater than $90 \%$ of lymph triglyceride was also found in this fraction.

Lipid extraction and assay. Whole lymph and lipoprotein were extracted in chloroform: methanol, $2: 1$, according to the procedure of Bragdon (6). Individual lipid classes were separated by TLC. Free and ester cholesterol bands were extracted in $10 \mathrm{ml}$ of chloroform and portions of this extract were taken to dryness under $\mathrm{N}_{2}$ before assay. Dried portions of free and intact ester cholesterol were assayed colorimetrically using the $o$-phthalaldehyde (ICN Nutritional Biochemicals) reagent of Zlatkis and Zak (7), according to the method of Rudel and Morris. ${ }^{3}$ Triglyceride containing bands were extracted with $10 \mathrm{ml}$ of chloroform:methanol, 2:1, and portions were taken to dryness before assay by the method of Van Handel and Zilversmit (8).

Portions of whole lymph, of lipoprotein solutions, of total lipid extracts, and of free and ester cholesterol extracts were taken for determination of radioactivity on a Unilux II liquid scintillation system (Nuclear-Chicago Corp., Des Plaines, III). Counting was carried out in an $18 \mathrm{ml}$ counting medium containing $2.67 \mathrm{~g}$ of 2,5-diphenyloxazole (PPO) and $133 \mathrm{mg}$ of 1,4-bis[2-(5-phenyloxazolyl) ]benzene (POPOP) per liter of toluene. When whole lymph and unextracted lipoprotein solutions were counted, $1 \mathrm{ml}$ of methanol was added with $25 \mu 1$ of sample to maintain a one-phase system. Counting efficiency was determined with an external standard using the channels ratio method for quench correction (9).

Statistical evaluation. The paired $t$ test $(10)$ was used to test for significant differences between the per cent esterification of exogenous and total cholesterol of chylomicra and VLDL.

\footnotetext{
${ }^{2}$ Rudel, L. L., M. D. Morris, and J. M. Felts. In preparation.

${ }^{3}$ Rudel, L. L., and M. D. Morris. Submitted for publication.
} 


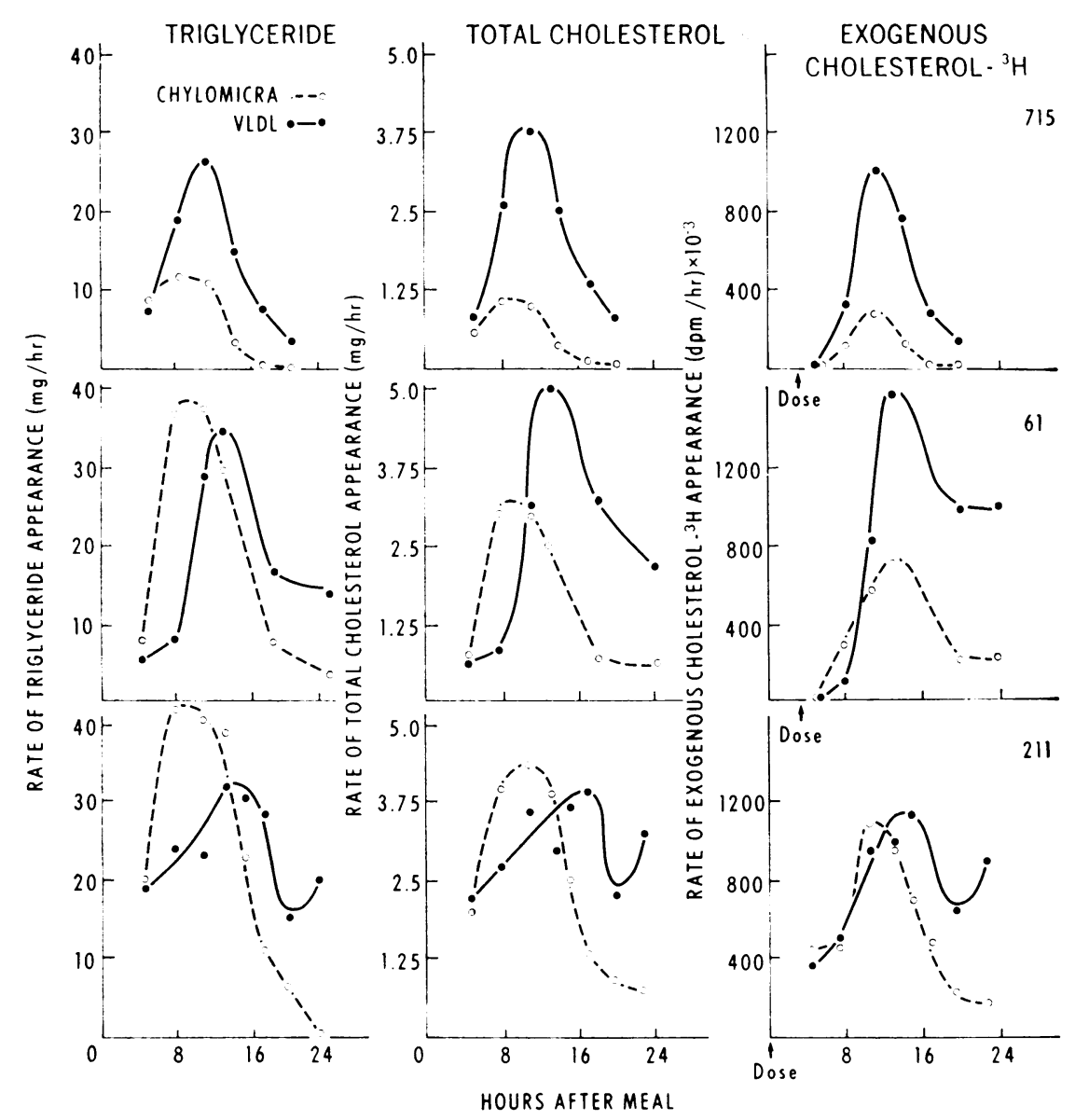

FIGURE 1 Rate of appearance of triglyceride, total cholesterol, and exogenous cholesterol- ${ }^{3} \mathrm{H}$ in lymph chylomicra and VLDL. Each point on the graph represents the midpoint of the collection interval. Animal 715 received the cholesterol ${ }^{3} \mathrm{H}$ dose $3 \mathrm{hr}$ after a meal as a micellar solution, animal 61 received the dose $3 \mathrm{hr}$ after a meal as an emulsion, and animal 211 received the dose as part of the meal. The triglyceride recovered in animals 715,61 , and 211 was 16,34 , and $46 \%$, respectively, of that ingested with the meal; average recovery was $30 \%$. The exogenous cholesterol recovered in animals 715,61 , and 211 was 14,34 , and $41 \%$, respectively, of the dose administered; average recovery was $30 \%$.

\section{RESULTS}

Appearance of cholesterol and triglyceride in $d<1.006$ lipoproteins of lymph. The rate of appearance of triglyceride in chylomicra and VLDL was used as an index of formation of these lipoproteins after a meal. Three typical patterns for triglyceride appearance are shown in Fig. 1. The maximum rate of appearance in chylomicra was between 8 and $12 \mathrm{hr}$ p.p. and preceeded the maximum rate of appearance of triglyceride in VLDL. Table I shows the total amount of triglyceride contained in chylomicra and VLDL of the 21-hr lymph collections (3-24 hr p.p.). During this period, an average of $55 \%$ of the triglyceride appeared in VLDL and $45 \%$ appeared in chylomicra. A relationship was found be- tween the rate of appearance and the total amount of triglyceride recovered in VLDL vs. chylomicra. When relatively less triglyceride was absorbed, as in animal 715 , the rate of appearance in chylomicra was lower than in VLDL. The per cent of recovered triglyceride in chylomicra for the entire collection period was only $31 \%$. In animal 211 , three times as much triglyceride appeared in the lymph collection as for animal 715 , and the rate of appearance of triglyceride in chylomicra exceeded that of VLDL throughout the early times. For the entire collection period, $50 \%$ of the recovered triglyceride was present in chylomicra. Thus, these results suggest that chylomicron formation occurs in response to the amount of triglyceride absorbed whereas VLDL formation remains much more constant. 
TABLE I

Cholesterol and Triglyceride Distribution between Lymph Chylomicra and VLDL

\begin{tabular}{|c|c|c|c|c|c|c|}
\hline \multirow{3}{*}{$\begin{array}{l}\text { Lipoprotein } \\
\text { lipid }\end{array}$} & \multicolumn{6}{|c|}{$\begin{array}{l}\text { Lipid* in } d<1.006 \text { lipoproteins } \\
\text { of } 21 \mathrm{hr} \text { lymph collection }\end{array}$} \\
\hline & \multicolumn{2}{|c|}{ Triglyceride } & \multicolumn{2}{|c|}{ Cholesterol } & \multicolumn{2}{|c|}{$\begin{array}{c}\text { Exogenous } \\
\text { cholesterol-3H }\end{array}$} \\
\hline & $m g$ & $\%$ & $m g$ & $\%$ & $d p m \times 10^{-3}$ & $\%$ \\
\hline $\begin{array}{l}\text { Chylomicra } \\
\text { VLDL }\end{array}$ & $\begin{array}{l}302 \pm 71 \\
339 \pm 54\end{array}$ & $\begin{array}{l}45 \\
55\end{array}$ & $\begin{array}{l}21 \pm 3.6 \\
37 \pm 4.2\end{array}$ & $\begin{array}{l}35 \\
65\end{array}$ & $\begin{array}{r}6,298 \pm 1,933 \\
13,514 \pm 2,267\end{array}$ & $\begin{array}{l}28 \\
72\end{array}$ \\
\hline Total & $641 \pm 124$ & & $58 \pm 7.1$ & & $19,873 \pm 4,123$ & \\
\hline
\end{tabular}

* Mean \pm SEM for five animals.

Fig. 1 shows that the rate of total cholesterol appearance in lymph chylomicra and VLDL parallels triglyceride appearance, although the rate of appearance in VLDL compared with that in chylomicra is proportionately higher for total cholesterol than for triglyceride. Table I shows that a greater percentage of total cholesterol than of triglyceride was carried in the VLDL. This was true for all animals studied and averaged $65 \%$. More total cholesterol was recovered in $\mathrm{d}<1.006$ lipoproteins of lymph than the amount of cholesterol fed with the meal, in spite of an average recovery of only $30 \%$ of exogenous cholesterol ${ }^{3} \mathrm{H}$.

Since chemically determined total cholesterol contains both exogenous and endogenous cholesterol, we used tritium-labeled exogenous cholesterol so that absorption of this form could be studied separately. The pattern of appearance of exogenous cholesterol was not identical with that of triglyceride or total cholesterol (Fig. 1). The rate of exogenous cholesterol appearance in VLDL was higher than the rate of triglyceride or total cholesterol appearance in VLDL (Fig. 1), and the total per cent of exogenous cholesterol recovered in VLDL was always greater, even in animals in which total triglyceride absorption differed threefold. Taken together, these data clearly demonstrate a preferential incorporation of exogenous cholesterol into VLDL.

The most dramatic demonstration that the VLDL is the most important transport vehicle of exogenous cholesterol during absorption was obtained when the per cent distribution of exogenous cholesterol between chylomicra and VLDL for each sequential lymph sample was determined in seven animals (Fig. 2). A progressive increase of exogenous cholesterol present in VLDL occurred for each sequential lymph collection. Over $80 \%$ of exogenous cholesterol was present in VLDL by $18 \mathrm{hr}$.

Chemical form of cholesterol in chylomicra and VLDL. The chemical form in which exogenous cholesterol appeared in lymph was studied by exanining the free cholesterol specific activity (FCSA) and the cholesterol ester specific activity (CESA) of both chylomicra and

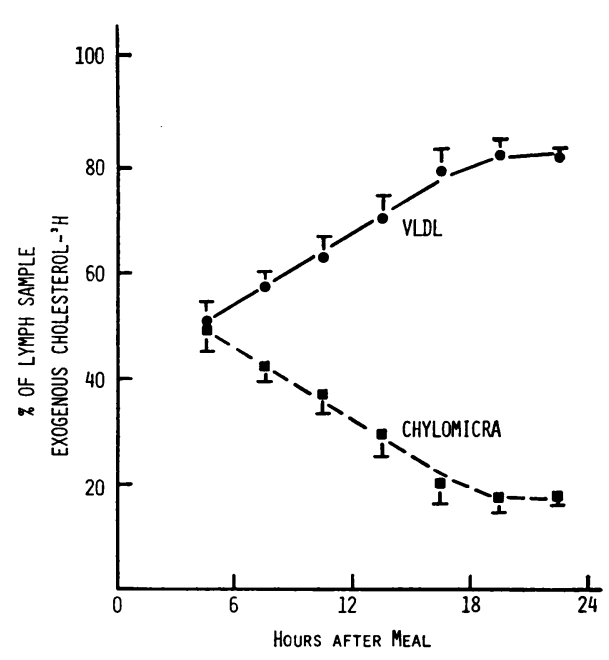

Figtre 2 Distribution of exogenous cholesterol- ${ }^{3} \mathrm{H}$ between chylomicra and VLDL of sequential lymph samples. Samples for each collection interval were fractionated into chylomicra and VLDL, and the distribution of cholesterol${ }^{3} \mathrm{H}$ was determined for each sample. Each point on the graph represents the midpoint of the collection interval. The mean $\pm \mathrm{SEM}$ is shown for seven animals.

VLDL of lymph. Fig. 3 shows the specific activity changes which occurred with time. In each animal, the CESA increased at a more rapid rate than FCSA. CESA exceeded the FCSA by two to fivefold at the observed maxima. CESA of VLDL exceeded those of chylomicra at the maxima for all animals studied. The same maximum CESA in VLDL was observed for two animals and was $1 \times 10^{6} \mathrm{dpm} / \mathrm{mg}$ while the maximum FCSA observed was $3 \times 10^{5} \mathrm{dpm} / \mathrm{mg}$.

A comparison was made between the per cent esterification of exogenous cholesterol- ${ }^{3} \mathrm{H}$ and of total cholesterol. Fig. 4 shows the results obtained in both chylomicra and VLDL isolated from sequentially collected lymph samples. The per cent esterification of exogenous
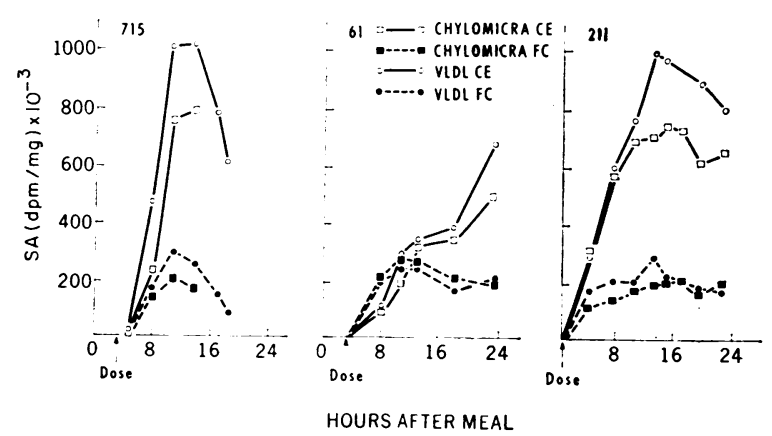

Figure 3 Time course of appearance of exogenous cholesterol $-{ }^{3} \mathrm{H}$ in free and ester cholesterol of lymph chylomicra and VLDL as shown by specific activity changes. Dose administration is described in Fig. 1. Each point of the graph represents the midpoint of the collection interval. 


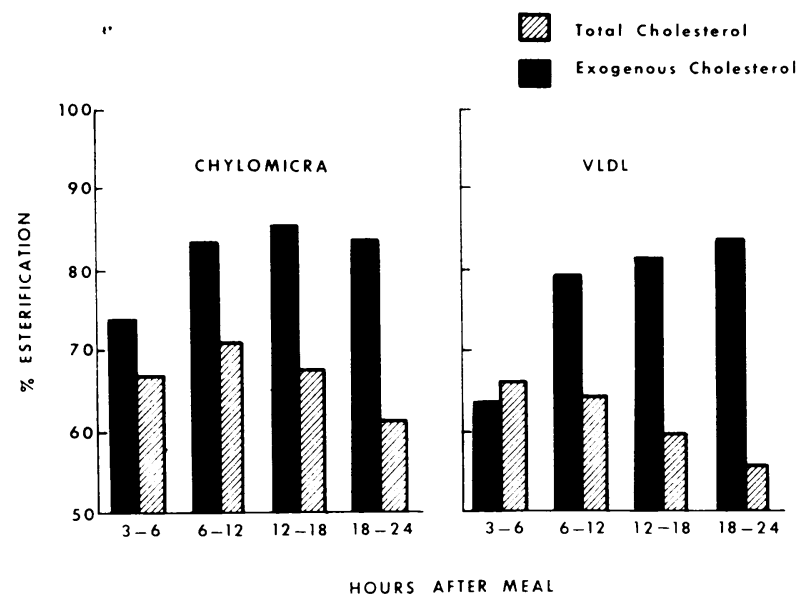

Figure 4 Esterification of total cholesterol and of exogenous cholesterol ${ }^{3} \mathrm{H}$ in lymph lipoproteins. Mean values for four animals are shown, so that the number of samples is 6-8 for each time interval except 3-6 hr where three samples were analyzed.

cholesterol- ${ }^{3} \mathrm{H}$ in both lipoproteins remained relatively constant except at the 3-6 $\mathrm{hr}$ interval during which only a small amount of cholesterol- ${ }^{3} \mathrm{H}$ appeared. A gradual decrease in the per cent of chemically determined total cholesterol present as ester cholesterol occurred with time. Cpon analysis using the paired $t$-test, the decrease with time in total cholesterol esterification was significant at the $P<0.01$ level for VLDL, while the decrease for chylomicra was not found to be statistically significant. When the per cent esterification of cholesterol- ${ }^{3} \mathrm{H}$ is compared with that of total cholesterol, significant differences at the $P<0.01$ level occurred at all but the 3-6 hr interval for both chylomicra and VLDL. These data demonstrate preferential esterification of exogenous cholesterol compared with total cholesterol.

\section{DISCUSSION}

It has only recently been recognized that the intestine is the site of synthesis of significant quantities of VLDL which may enter the circulation (11-14). However, only one report has suggested that the VLDL may be important in cholesterol transport in lymph (2) and exogenous cholesterol per se was not studied in those experiments. A comparison of the transport of exogenous cholesterol in lymph chylomicra and VLDL after i single meal was carried out in low cholesterol-fed rabbits. Our data clearly show that VLDL is the major transport vehicle for exogenous cholesterol in this species. A preferential incorporation of exogenous cholesterol into VLDL was demonstrated in at least three ways. First, the per cent of exogenous cholesterol of lymph present in VLDL continuously increased with time after a meal until, at later times, $80 \%$ or greater was present in VLDL (Fig. 2). Second, the per cent of exogenous cholesterol $-{ }^{3} \mathrm{H}$ recovered in lymph VLDL was consistently higher than the per cent of triglyceride and total cholesterol recovered in VLDL (Table I). This was found to be true even when the total amount of absorbed triglyceride changed threefold. Third, the maximum rate of appearance of exogenous cholesterol in VLDL compared with its maximum rate of appearance in chylomicra is proportionately greater than the maximum rates of appearance of triglyceride and total cholesterol in these two lipoproteins (Fig. 1). The present studies establish an important role for VLDL in exogenous cholesterol transport in lymph of the rabbit and provide additional evidence that the intestine is an important site of VLDI, synthesis.

Our results elucidate some specific aspects of the mechanism of exogenous cholesterol absorption by the intestinal mucosal cell. We can visualize the following hypothetical model: Exogenous and endogenous free cholesterol in the intestinal lumen is solubilized by incorporation into micelles, and in this micellar phase these sources of cholesterol become indistinguishable. Micellar free cholesterol crosses the brush border of the mucosal cell (15). Since complete equilibration of exogenous and endogenous cholesterol was not observed, esterification probably occurs immediately after the exogenous (micellar) cholesterol crosses the brush border. In this context, it has been reported by David. Malathi, and Ganguly (16) that the intestinal mucosal cell in rats has a cholesterol esterifying enzyme on the inside of the brush border. Upon esterification, absorbed micellar cholesterol is effectively separated inside the cell from endogenous cholesterol pools. Since the ratio of free to ester cholesterol ${ }^{3} \mathrm{H}$ is maintained at 1 to 4 in the face of changing mass and specific activity, it follows that the exogenous free cholesterol within the cell must also be maintained in a chemically or physically distinct pool. Exogenous cholesterol is subsequently incorporated into chylomicra and VLDL which then enter lymph. During formation of chylomicra and VLDL, free endogenous cholesterol synthesized within the mucosal cell is incorporated into these lipoproteins, probably as part of the outer coat (17), which accounts for the lower FCSA than CESA.

Such a hypothesis is consistent with a dilution of litbeled dietary cholesterol by endogenous cholesterol from at least four sources; namely, from cholesterol present in bile. from cholesterol present in sloughed cells, from the cholesterol synthesized in the intestinal mucosal cell and by free cholesterol exchange with $\mathrm{d}>1.006$ lipoproteins of lymph. Our data enable us to calculate relative contributions of individual endogenous cholesterol sources (Table II). The values for the maximal specific activities of free and ester cholesterol of lymph chylo- 
micra and VLDL were used since these values probably are the closest approximation to a steady-state condition. The average amount of total cholesterol appearing in the lymph $\mathrm{d}<1.006$ lipoproteins was $58 \mathrm{mg}$ (Table I). An average of $64 \%$ of total cholesterol was esterified (Fig. 4 ), so that approximately $37 \mathrm{mg}$ of the recovered cholesterol of lymph $\mathrm{d}<1.006$ lipoproteins was cholesterol ester and $21 \mathrm{mg}$ was free cholesterol. The CESA maximum was $1 \times 10^{6} \mathrm{dpm} / \mathrm{mg}$ in VLDL and was $55 \%$ of the dietary cholesterol specific activity $(30 \mu \mathrm{Ci}$ cholesterol${ }^{3} \mathrm{H} / 36 \mathrm{mg}$ dietary cholesterol $=1.8 \times 10^{6} \mathrm{dpm} / \mathrm{mg}$ ). On this basis, $20 \mathrm{mg}$ of cholesterol ester originated in the diet and $17 \mathrm{mg}$ were of endogenous origin. According to our hypothesis, the endogenous micellar free cholesterol within the intestinal lumen is the precursor of endogenous lymph $\mathrm{d}<1.006$ lipoprotein cholesterol ester. The maximum FCSA in lymph was $3 \times 10^{5} \mathrm{dpm} / \mathrm{mg}$ which is $17 \%$ of dietary cholesterol specific activity. Thus, for free cholesterol present in lymph $\mathrm{d}<1.006$ lipoproteins, $4 \mathrm{mg}$ originated in the diet and $17 \mathrm{mg}$ were of endogenous origin. This gives a calculated free cholesterol/ester cholesterol ratio for exogenous cholesterol of $4 / 20$. Assuming the endogenous micellar cholesterol of the lumen is equilibrated and behaves in identical fashion with exogenous cholesterol in micelles, the same factor must be applied to determine the amount of endogenous luminal cholesterol which appeared in the lymph as free cholesterol. Thus, $3 \mathrm{mg}$ of the endogenous free cholesterol recovered in lymph $\mathrm{d}<1.006$ lipoproteins probably originated from luminal cholesterol and $14 \mathrm{mg}$ probably originated in the intestinal mucosal cell. Based on the small amount $(<5 \%)$ of exogenous cholesterol ${ }^{3} \mathrm{H}$ recovered in $\mathrm{d}>1.006$ lipoproteins of lymph, it is assumed that the exchange of free cholesterol between chylomicra and VLDL and $d>1.006$ lipoproteins would not significantly affect the calculation. Therefore, for these calculations $41 \%$ or $24 \mathrm{mg}$ of the cholesterol recovered in lymph was of exogenous origin, i.e., from the diet, and $59 \%$ or 34 $\mathrm{mg}$ was of endogenous origin. Of the $34 \mathrm{mg}$ of endogenous cholesterol, $59 \%$ or $20 \mathrm{mg}$ originated in the intestinal lumen, probably from bile cholesterol since Wilson and Reinke (18) have shown that little sloughed cell cholesterol is reabsorbed from the lumen. The other $41 \%$ or $14 \mathrm{mg}$ of endogenous cholesterol originated from the intestinal mucosal cell probably via de novo synthesis.

Thus, the present studies demonstrate that exogenous cholesterol is transported preferentially in VLDL rather than in chylomicra in thoracic duct lymph of low cholesterol, moderate fat-fed rabbits. The formation of lymph VLDL and chylomicra appeared to be at least partially dependent on the amount of triglyceride absorbed and increased rates of appearance of chylomicra were found when the amount of absorbed triglyceride increased. In both lymph VLDL and chylomicra, exogenous cholesterol
TABLE II

Endogenous and Exogenous Cholesterol Distribution

\begin{tabular}{ccc}
\hline & \multicolumn{2}{c}{ Lymph d $<1.006$ lipoprotein } \\
\cline { 2 - 3 } & $\begin{array}{c}\text { Ester } \\
\text { cholesterol }\end{array}$ & $\begin{array}{c}\text { Free } \\
\text { cholesterol }\end{array}$ \\
\hline Total* in lymph & $m g$ & $m g$ \\
From exogenous $\ddagger$ & 37 & 21 \\
From endogenous & 20 & 4 \\
Luminal & 17 & 17 \\
Mucosal & 17 & 3 \\
\end{tabular}

* Total cholesterol appearing in lymph over the $21 \mathrm{hr}$ collection period was $58 \mathrm{mg}$ (Table I).

$\ddagger$ The calculated per cent of total cholesterol appearing in lymph was $59 \%$ endogenous and $41 \%$ exogenous.

was preferentially esterified. The per cent esterification of exogenous cholesterol remained constant with time in the face of a changing specific activity and a changing rate of appearance, while the per cent esterification of total cholesterol decreased. These data suggest that the intestinal mucosal cell has a mechanism to recognize and maintain the newly absorbed exogenous cholesterol in a separate compartment from the endogenous mucosal cell cholesterol.

\section{ACKNOWLEDGMENTS}

The authors wish to thank Miss Irene Fryz for her skilled technical assistance.

This study was supported by Grant MT-4215 from the Medical Research Council of Canada, by National Institutes of Health Grant GM-37164, by the Banting Research Foundation, and by the Ontario Heart Foundation.

\section{REFERENCES}

1. Clarkson, T. B. 1963. Atherosclerosis-spontaneous and induced. Adv. Lipid Res. 1: 211.

2. Zilversmit, D. B., F. C. Courtice, and R. Fraser. 1967. Cholesterol transport in thoracic duct lymph of the rabbit. J. Atheroscler. Res. $7: 319$.

3. Goodman, D. S. 1965. Cholesterol ester metabolism. Physiol. Rei. 45 : 747.

4. deVries, B., and G. Jurriens. 1963. Use of silica gel impregnated with silver nitrate for the separation of lipids by thin-layer chromatography. Fette Seifen Anstrichm. $65: 725$.

5. Noble, R. P. 1968. Electrophoretic separation of plasma lipoproteins in agarose gel. J. Lipid Res. 9: 693.

6. Bragdon, J. H. 1960. Extraction of lipids from serum. A. General considerations. In Lipids and the Steroid Hormones in Clinical Medicine. F. W. Sunderman and F. W. Sunderman, Jr., editors. J. B. Lippincott Co., Philadelphia. 6.

7. Zlatkis, A., and B. Zak. 1969. Study of a new cholesterol reagent. Anal. Biochem. 29 : 143. 
8. Van Handel, E., and D. B. Zilversmit. 1957. Method for the direct determination of serum triglycerides. J. Lab. Clin. Med. 50: 152.

9. Peng, C. T. 1970. A review of methods of quench correction in liquid scintillation counting. In The Current Status of Liquid Scintillation Counting. E. D. Bransome, Jr., editor. Grune \& Stratton, Inc., New York. 283.

10. Weinberg, G. H., and J. A. Schumaker. 1962. Statistics An Intuitive Approach. Wadsworth Publishing Co., Inc., Belmont, Calif.

11. Baxter, J. H. 1966. Origin and characteristics of endogenous lipid in thoracic duct lymph in rat. J. Lipid Res. $7: 158$.

12. Roheim, P. S., L. I. Gidez, and H. A. Eder. 1966. Extrahepatic synthesis of lipoproteins of plasma and chyle: role of the intestine. J. Clin. Invest. 45: 297.
13. Windmueller, H. G., and R. I. Levy. 1968. Production of $\beta$-lipoprotein by intestine in the rat. J. Biol. Chem. 243: 4878 .

14. Ockner, R. K., F. B. Hughes, and K. J. Isselbacher. 1969. Very low density lipoproteins in intestinal lymph: origin, composition, and role in lipid transport in the fasting state. J. Clin. Invest. $48: 2079$.

15. Treadwell, C. R., and G. V. Vahouny. 1968. Cholesterol absorption. Handb. Phy'siol. 3 : 1407.

16. David, J. S. K., P. Malathi, and J. Ganguly. 1966. Role of intestinal brush border in the absorption of cholesterol in rats. Biochem. J. 98: 662 .

17. Zilversmit, D. B. 1968. The surface coat of chylomicrons: lipid chemistry. J. Lipid Res. 9: 180.

18. Wilson, J. D., and R. T. Reinke. 1968. Transfer of locally synthesized cholesterol from intestinal wall to intestinal lymph. J. Lipid Res. 9: 85. 